\title{
"WHAT IS THE GRASS?": THE ROOTS OF WALT WHITMAN'S CEMETERY MEDITATION
}

\author{
Desirée Henderson
}

ONE OF THE MOST MEMORABLE MOMENTS in Walt Whitman's "Song of Myself" is the section known as "What is the grass?" Named after the question that initiates the poet's musings, this part of Whitman's sprawling poem is considered by many to illustrate themes central to the entire text: the innocent inquisitiveness of the poetic mind, an emphasis upon the multiplicity and diversity of perception, the reunion of living and dead through a shared natural environment, and, above all, the symbolism of the grass as a democratic plant linking all people through and to nature. While the passage is typical of Whitman's expansive style and ranges from nature to God to rebirth, the reader can identify a concrete setting for the scene: a cemetery. The poet appears to stand amid grasscovered graves, envisioning the space of the cemetery as a metaphor for the interrelationship between humanity and nature. Our understanding of this passage and indeed of the entire poem can be enhanced by going beyond this general locale to examine a specific material space Whitman may have been referencing in the passage: a rural cemetery. In this essay, I locate the roots of Whitman's idyllic poetic space in the real space of the rural cemetery and suggest that by knowing the history and literature of these innovative memorial spaces, we may know more about Whitman, "Song of Myself," and the literary culture of the era.

In nineteenth-century America, burial within urban graveyards was gradually curtailed and the dead were relocated from the heart of the city to a suburban locale, the rural cemetery. Elements of the sentimental mourning culture that characterized the time, the cemeteries sought to beautify death by providing the grief-stricken with a picturesque setting in which to savor the bittersweet experience of loss. Inspired by renowned European cemeteries like Père Lachaise in Paris, these garden cemeteries were characterized by their preservation of the natural landscape through an informal layout of roads and paths, accenting natural attributes like hills, lakes, and streams, and artfully distributing tombstones and statues within the park-like setting. The impact that these memorial, spatial, and horticultural changes had upon American culture was profound. By 
relocating burial to spaces distanced from everyday life, they reflected the growing belief in a link between decay and disease and affirmed new sanitary practices. By cultivating trees, shrubs, and grassy lawns as essential elements of a cemetery, they ushered in a taste for stylized landscaping that came to dominate American gardening. As some of the most popular tourist attractions of the era, they reflected the leisure practices of the rising middle class and presaged the city parks movement. By popularizing elaborate memorial statuary, they anticipated a public monument craze in the post-Civil War era. ${ }^{1}$

In addition, rural cemeteries had a literary presence in nineteenthcentury America that has not been fully appreciated, forming a body of writing that I loosely term "cemetery literature." In contrast to canonical works of American "graveyard poetry" such as William Cullen Bryant's "Thanatopsis" that situate death within symbolic or universal settings, these texts are rooted in the landscapes and histories of specific cemeteries. This is particularly true of two of the earliest and most prominent rural cemeteries, Mount Auburn in Cambridge, Massachusetts, and Green-wood in Brooklyn, New York, both of which achieved a remarkable ubiquity in popular and literary publications of the era. Each has a textual history that parallels their development: public speeches and pamphlets soliciting the cemetery's creation; documents of corporate formation and financial growth; and directories, guidebooks, and maps for their visitors and customers. The number and variety of these publications is remarkable: Green-wood Cemetery, for example, lists thirteen official publications between 1839 to $1866,{ }^{2}$ while Mount Auburn even produced a short-lived weekly periodical titled The Mount Auburn Memorial from 1859 to 1860 . The pinnacle of this publishing history was a series of elaborate illustrated editions and histories-Mount $\mathrm{Au}$ burn Illustrated (1847) and Green-wood Illustrated (1847), as well as $A$ History of Mount Auburn (1860) and Green-wood Cemetery: A History of the Institution (1866) - large, ornately bound, and gilt-edged books that are replete with line engravings of each cemetery's celebrated tombstones and natural features.

The rural cemeteries were also covered extensively in local and national periodicals. Hundreds of articles documented, reviewed, and evaluated the rise of the cemeteries. Often the boundary line between journalism and advertisement is difficult to delimit in these pieces as newspapers would commonly reprint a cemetery's own propaganda. In addition, rural cemeteries inspired countless aspiring and established poets to pen odes, sonnets, and elegies with titles like "Meditations in Mount Auburn" or "Lines Written on Visiting Green-wood Cemetery." The pervasive presence of Mount Auburn and Green-wood cemeteries in American periodicals indicates that, although the cemeteries were designed to service their immediate communities, in textual form they 
achieved a national significance, inspiring the construction of rural cemeteries from coast to coast and shaping the image of the modern cemetery within the popular imaginary. By the end of the century, to write of death in a materially grounded way was to engage on some level with the dominant trend of the rural cemetery movement and, in particular, the recurring images of Mount Auburn and Green-wood cemeteries.

In this essay, I outline the formulaic representation of the rural cemeteries, suggesting that the heterogeneity of nineteenth-century American memorial practices and burial spaces was rendered uniform within cemetery literature. While not downplaying the other social and literary forces at work in the development ofWalt Whitman's poetic voice, I nevertheless believe that the idyllic cemetery promoted by the rural cemetery movement serves as an important backdrop for the poet's representation of spaces of death, burial, and remembrance. Harold Aspiz's recent study, So Long!: Walt Whitman's Poetry of Death, has demonstrated the extent to which death and mourning defined Whitman's writing, as the poet actively engaged with the belief systems and rituals surrounding death in nineteenth-century culture. ${ }^{3} \mathrm{My}$ account of the conventions of cemetery literature provides an additional context for interpreting Whitman's poetry, particularly the "What is the grass?" section of the 1855 "Song of Myself." By situating the passage within the emerging landscape of the rural cemetery, it is possible to better comprehend the contours of Whitman's representational choices: I show that Whitman invokes the well-known features of the rural cemetery and the scripted responses to the space in order to establish a common ground with his readers. However, this shared landscape is destabilized when Whitman redirects the audience's perspective from the superficial natural environment to the complexity beneath the surface. In his imaginary cemetery, it is the dead who take center stage and whose post-mortem experiences prompt a revelation about the nature of existence itself.

Cemetery literature established the need and value of rural cemeteries primarily through the technique of vilifying urban graveyards and the cities in which they were located. Authors deployed the image of overcrowded, noxious graveyards surrounded and impeded upon by hordes of urban residents. One early cemetery promoter exclaims,

Why should we measure out a narrow portion of death for our graveyards in the midst of our cities, and heap the dead upon each other with a cold, calculating parsimony, disturbing their ashes, and wounding the sensibilities of the living? Why should we expose our burying-grounds to the broad glare of day, to the unfeeling gaze of the idler, to the noisy press of business, to the discordant shouts of merriment, or to the baleful visitations of the dissolute? ${ }^{4}$ 
These statements establish an opposition between the busy, noisy and unfeeling space of the city and the tender sentiment of the bereaved. Works like these call upon their audiences to demonstrate their respect for the grief-stricken by providing them with an appropriate and sacred space for burial, a practice (they argue) common to the civilized societies of Biblical and Classical times (an association reinforced by the Egyptian and Grecian design of memorial statuary within the cemeteries). These depictions of the city correspond to popular discourse of the time in which the modern city and its inhabitants were represented as dangerous, dirty, corrupt, and materialistic - legacies of the explosive population growth that accompanied urbanization. In cemetery literature, these familiar images were employed to render the city essentially incompatible with sentimental mourning practices. Rural cemetery advocates encouraged not urban reform but removal, a precipitous flight from the heterogeneous and chaotic cityscape that implicitly condoned the growing class distinctions between the people who lived in the city and those who increasingly lived outside it. The movement of the dead to the suburbs was one of the first indicators of a new landscape of privilege that divided the urban poor and the suburban elite. Cultural theorists including Michel Foucault and Joseph Roach have identified this relocation of the dead as one expression of a large-scale redefinition of space in the nineteenth century. ${ }^{5}$ The work of cemetery literature was to overcome resistance to these changes, to explain and justify them as natural elements of social development, and even to celebrate them as the highest accomplishments of a civilized people.

Rural cemeteries proposed to solve the problems of the city by constructing a natural space distanced from the bustle and din of urban life. The cemeteries emphasized their distinction from urban space even through their names, which tend towards mono-syllabic geographical references: Cypress Hill, Oakwood, Mount Hope, Spring Grove, and so on. The founders of Green-wood Cemetery indicated that they considered but ultimately rejected the term "necropolis" or city of the dead because it "savours of art and classic refinement, rather than of feeling," whereas Green-wood conveys "verdure, shade, ruralness, natural beauty; everything, in short, in contrast with the glare, set form, fixed rule and fashion of the city." Cemetery literature cultivated the idea that the delicate sensations of mourning could only be experienced in a natural setting. It was in relation to natural features like trees, grass, lakes and streams that the visitor could escape the worries of life or the pangs of grief and enter into a heightened state of peace and reflection. Writes one admirer, "the influence of the place is not a melancholy or a saddening influence; it is better-it is expansive and soothing, filling the mind with the beauties of nature, and thus breaking the force of any passionate expressions of affliction." 
While cemetery literature is replete with images of the natural environments for which the cemeteries were famous, it also reveals how carefully that environment was constructed. The encouraged escape from urban space does not take the form of fleeing civilization for wild, untamed nature; rather, these authors celebrated a controlled, organized, and landscaped nature with the understanding that, while nature can transport the feelings, it requires some assistance in achieving this effect. One supporter declares, "Nature, under all circumstances, was meant to be improved by human care; it is unnatural to leave it to itself." 8 This devotion to managing nature is particularly evident in the layout of the cemetery's paths and roads. The founders of Mount Auburn Cemetery eschewed the familiar geometrical design of graveyards in favor of curves and asymmetry, characterized as "avenues [that] are winding in their course and exceedingly beautiful in their gentle circuits ... producing charming landscape effects from their natural arrangements, such as could never be had from straightness or regularity," Green-wood, "undulations and graceful curvatures" which have "effectively precluded the rigid sameness, that tiresome iteration, which must always attach to long lines and broad fields of unvarying parallelograms." 10 Maps of the cemeteries, often reproduced as illustrations, highlight the curve as a feature of nature in contrast to the structured design of urban space (see Figure 1). These images portray the cemeteries as soft and

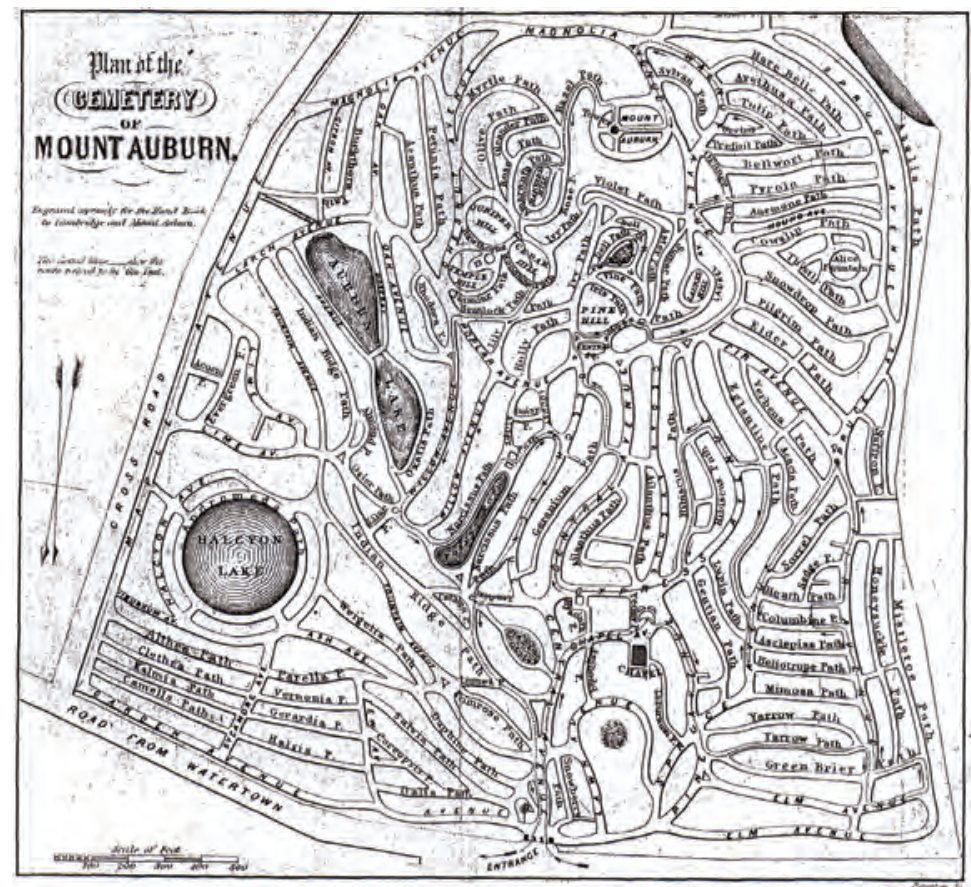

Figure 1. 
organic, a visual aesthetic that promises an ease of movement through space. While appearing to demonstrate the cemetery's deep allegiance to nature, these winding paths were, of course, the result of careful planning and laborious construction that imposed an artificial order upon the landscape. (Ironically, the curved and intersecting roadways also necessitated maps and guidebooks, as visitors were easily lost in the labyrinthine spaces. ${ }^{11}$ ) The design of the paths indicates how the cemeteries sought to make it possible for a general populace to enter and traverse natural space, to make nature both accessible and safe. In doing so, the cemeteries promoted a taste for landscaping. "All rural cemeteries also exert an important influence on the public taste," says one writer in the Horticulturalist and fournal of Rural Art and Rural Taste, who instructs members of all classes on the beauty of nature: "how beautiful in her own simplicity, and also when her charms are heightened by the hand of art." ${ }^{12}$ In passages like these, the role of the cemetery as a repository for corpses is deliberately overwritten in favor of a role as a mediator between the public and nature.

This artfully designed and manipulated natural landscape was intended to provoke a sentimental experience in the cemetery's visitors, a highly constructed space designed to produce a constructed emotional response. The cemeteries promised to elevate the spirit by allowing the living to encounter only the beautiful side of death, a vision of death that promoted the value of life. In this way, the cemeteries sought to use the space of death as a lens through which to view life itself. The cemetery visitors were prompted - as the reading audience was as well-to look anew upon life from the vantage point of the grave, a trope of perspective that is manifestly enacted in textual form through the image of looking back on the city from the viewpoint of the cemetery. Both Mount Auburn and Green-wood were constructed on hills distanced from their neighboring metropolises, a physical feature that enters the literature as a recurring scene: "Below us lies Brooklyn, with its rural outposts and pleasant surroundings; while beyond the glittering water, far as the eye can reach, stretches the Emporium of the New World - the great island city [New York City]." "13 Depictions of the celebrated panoramas visible from each cemetery also indicate an ideological perspective on the role of death in the emotional growth of the living: it is by being with the dead that the living can gain new eyes through which to regard and value their own lives. ${ }^{14}$

What is striking about this sentimental trope is how the cemetery literature repeatedly asserts that it is not limited to mourners, those intimately attached to the dead who visit the cemetery to visit specific graves. Instead, cemetery literature promises the universal potential of this transcendent awakening, a democratic ideal that permeates every 
element of the cemeteries in both design and depiction. The cemeteries were initially conceived as corporations with each lot owner considered an equal member of the overall corporate ownership and management of the cemetery. Cemetery literature repeatedly declares that all the interred are treated as equally deserving of commemoration; as one visitor writes:

I had imagined white marble, the show and glare of wealth, stately and expensive monuments, and that aristocratic expenditure ... [i]n a word, I had imagined those broad distinctions which the rich are so generally disposed to carry even to the monuments and garniture of the house appointed for all the living. No such repulsive a show was here ... [Mount Auburn] seems a sort of public declaration, that in an age of scrip, avarice, corporations, and brass, some still retain heart and memory and the gentle and sacred thoughts that unite us with the departed. ${ }^{15}$

This author celebrates the cemetery for the ways it treats all the dead equally, regardless of wealth or social status, even encouraging a simplistic or humble mode of commemoration. In one of the many poems that the popular poet Lydia Sigourney composed on rural cemeteries, she extends this democratic impulse even further and depicts the cemetery as the destination of individuals from across the globe: "A ceaseless tide of emigration flows / On through thy gates, for thou forbiddest none."16

Moreover, the cemeteries are represented as democratic in terms of their effects. Repeatedly, cemetery literature depicts a variety of Americans gathering at the cemetery who become united despite their apparent differences. One writer describes this occurrence as one member of a "gay party . . . full of life, and health, and beauty," joins an "ennuyée," a husband and wife recently bereaved of their child, a citizen and a stranger at Mount Auburn. This socially diverse crowd is drawn together by their shared location: “. . . when you are once within the enclosure, Fashion and the World, and Gaiety and Splendor, are soon forgotten. ... The visitors, too, one and all, no matter what their mood when they reached the gate-way, are at once sobered and subdued, as soon as they have passed under these gathering shades"(G.T.C. 316). The social differences are eclipsed by the sacred function of the space, which reveals an essential humanity within each of the visitors.

Of course, the realities of access to the rural cemetery may not have always lived up to these democratic ideals either in terms of burial or visitation. While the cemeteries described themselves as non-denominational, they were essentially Protestant, and Catholic and Jewish communities continued to utilize their own graveyards. While they claimed to be open to individuals of all walks of life, the interred were almost exclusively members of the upper or middle class; the price of burial plots was steep, well beyond the means of most Americans. In fact, as the 
popularity of the cemeteries ascended, plot ownership and extravagant monument design became status symbols within elite society. And, while the cemeteries had no stated restrictions on race, both interred and visitors were overwhelmingly white. Special plots were sometimes set aside for blacks or the poor, a segregated structure that closely mirrored the segregation that characterized American society as a whole. ${ }^{17}$

Similar limitations were placed upon who could visit the cemeteries. Despite the previous author's image of a diverse group of Americans gathering at the gates of Mount Auburn Cemetery, the reality was that access to the cemeteries was strictly regulated. Mount Auburn's early practices of "promiscuous admittance" were replaced by admittance to lot-owners and their families only, who were required to show a ticket for entry. Each ticket included a list of rules of behavior that prohibited unsuitable activities ranging from "unseemly noises," speeding carriages, unfastened horses, gathering flowers, writing on or defacing monuments, discharging firearms, and so on. ${ }^{18}$ The fact that such regulations were required indicates that the use of the space had to be enforced-quiet meditation was neither the "natural" nor immediate reaction of all visitors. The contrast between the constructed image of the space and the reality of its access and use reveals the interplay between the representations of the cemeteries and the cemeteries themselves; in textual form, the cemeteries could achieve an idealized form and function not possible in reality.

One final feature of these texts deserves mention: the goal of cemetery literature was to replicate as closely as possible the experience of visiting the cemeteries themselves. The primary technique for achieving this effect was that of placing the reader into the imaginative landscape of the cemetery, affecting verisimilitude between text and place. In this way, periodical representations of the rural cemeteries enabled their middleclass readers to gain access to upper-class spaces. Repeatedly authors address the reader as if he or she stood within the cemetery: "Reader, let us go, too. . . Reader, you may not have been there, if not a dweller in the neighborhood; or, if you have, it cannot be unwelcome to stroll with us again through the grounds ... now we have wound our way up to the hill-top, let us pause, and look around and think" (G.T.C. 316, 318). This passage exemplifies the intention of replicating the physical experience of the cemetery by engaging the reader in an imaginative interaction with the landscape. It also partakes of the desire to control or direct the reader's experience, leading him or her along particular paths, pointing out specific sites worthy of notice. In this way, the works of cemetery literature reflect the rise of guidebooks and maps which sought to act as a comprehensive grid over the landscape. 
Just as the number of visitors and annual revenues of the cemeteries attest to their unprecedented popularity, the number and variety of literary works devoted to the cemeteries attests to their literary significance. Yet, while historians acknowledge the impact that the rural cemeteries have had upon American society, the importance of the literary depiction of these spaces has yet to be fully explored. In the following pages, I argue that cemetery literature provides a key context for interpreting Whitman's poetic depiction of the cemetery in "Song of Myself." While my analysis focuses upon a single representative author and text, these claims provide some ways of thinking about the ubiquitous presence of Mount Auburn and Green-wood Cemetery in American literature, for these two cemeteries are recurring landmarks. A few of the wellknown authors who specifically refer to them are: Lydia Maria Child in Advice to Mothers (1831); Nathaniel Hawthorne in "The New Adam and Eve" (1843), Catherine Maria Sedgwick in "New York Fountains and Astor Baths" (1844), Fanny Fern in "Incident at Mount Auburn" (1853) and "Green-wood and Mount Auburn" (1857), Mark Twain in Innocents Abroad (1869), Horatio Alger in Ragged Dick (1867) and Edward Bellamy in Looking Backward (1887). Even Emily Dickinson wrote about her visit to Mount Auburn in $1846 .{ }^{19}$ The fact that these cemeteries appear repeatedly in the writing of such a diverse group of American authors is a testament to the fact that they deserve attention as influential spaces within a nineteenth-century literary culture that established a conventional relationship between death, society, and the natural environment.

One young journalist who participated in the widespread periodical coverage of the rural cemetery movement was Walt Whitman. Whitman's early career as a newspaper man in Brooklyn perfectly placed him to be an observer of and commentator on Green-wood Cemetery. Whitman wrote about Green-wood no less than seven times in the years before he published Leaves of Grass in $1855 .{ }^{20}$ Some of these articles merely mention the cemetery as a recognizable Brooklyn landmark, but four are extended depictions of Green-wood in the early years of its development and shed light upon Whitman's knowledge of and response to the dominant modes of depicting the memorial space. Whitman's pieces have little to distinguish them from the mass of journalistic accounts of the cemetery and are guilty of many of the faults that have sentenced other articles to obscurity: they are repetitious and propagandistic, and are usually pieced-together versions of previously printed articles rather than original compositions. My analysis suggests however that Whit- 
man's writings about Green-wood in a journalistic forum establish an important background for his later poetry, demonstrating that he was influenced by the broad conventions I outlined above in his own depiction of the cemetery.

The relationship between Whitman's journalism and his poetry has long been a subject of interest for literary scholars. Whitman worked as a freelance journalist in over twenty Brooklyn and New York periodicals and then as editor of eight newspapers including the Brooklyn Daily Eagle and NewYork Aurora before turning to poetry. Even after the publication of Leaves of Grass and, indeed, throughout his lifetime, he continued to contribute articles and reviews to newspapers across the country. Most scholars agree that Whitman's immersion in the newspaper industry had a significant impact upon both the form and content of Leaves of Grass. Thomas sums up the scholarship on this subject: "Implicit in these forms of study is the belief that his journalistic prose and his poetry are two fundamentally different but essentially complementary ways of mediating the modern, of articulating - by means either direct or symbolic - the character of life in his time." ${ }^{21}$ Whitman himself endorses this approach, stating, "The fifteen years from 1840 to 1855 may be considered as the gestation-years, or period of formation, out of which Leaves of Grass rose." ${ }^{22} \mathrm{My}$ analysis thus follows from the understanding that Whitman's journalism can be seen as a literary forum in which he rehearsed the themes of his later poetry. Whitman's newspaper articles on Green-wood Cemetery, while only a tiny fraction of his vast journalistic production, support the view that there is a relationship between his newspaper writing and his poetry, as inchoate versions of themes and spaces that were to figure largely in his poetic vision of America.

Whitman's early journalistic accounts of Green-wood Cemetery reproduce almost exactly the tropes and imagery that characterize cemetery literature. He affirms the distinction between urban and suburban space and celebrates the natural setting as ideal for provoking sentimental feelings, writing "While standing upon this consecrated ground, I was led into a train of reflections at once pleasing, yet melancholy. How solemn are the thoughts that arise in the mind! What a profound calm pervades the whole scene!" (Fournalism 1:9). He supports the idea that the cemetery will benefit individuals from every walk of life, not merely the recently bereaved: "The effect were good, truly, if the whole mass of our population - the delver for money, the idler, the votary of fashion, the ambitious man - if all could, ofttimes, move slowly through that Beautiful Place of Graves, and give room to the thoughts that would naturally arise there" (1:421-422). He adopts the technique of direct address, "Have you ever been to Green-wood, dear reader?" (1:421), and admires the view of the city from the highest point in the cemetery 
(1:9). These familiar images indicate Whitman's awareness not only of Green-wood as a physical space (which he clearly visited on more than one occasion) but as a rhetorical site. Likewise, it is clear that Whitman was capable of replicating the imagery and literary techniques common in cemetery literature. Thus, his use of or rejection of these tropes is significant and sheds light on his depiction of the space of burial and commemoration in "Song of Myself."

Whitman's engagement with the rural cemetery movement is most evident when he depicts spaces of burial as in the "What is the grass?" section. Our understanding of this passage is enhanced if we consider that the events unfold in a space with a history, a material form, and a literary tradition. When Whitman situates the nineteenth-century reader within a cemetery setting, he is drawing upon a shared vocabulary or set of images largely informed by the rural cemetery movement. Whitman's innovation is to redirect the reader's gaze from a panoramic view of the landscape towards a glimpse into the afterlife. Whitman moves beyond the superficial beauty of the rural cemetery when he literally goes underground, trading surface for depth. This new perspective enables the poet to look directly at the dead, to comprehend and appreciate their physicality, and to promote a vision of the afterlife as benevolent and even desirable.

This section of the poem has become known by its introductory phrase, "A child said, What is the grass?," and achieves an internal coherence as each lines flow from this question as a series of interrelated responses. Aspiz speculates that Whitman originally composed it as a stand-alone poem that was folded into "Song of Myself," a possibility that is formalized after the first edition when it becomes the distinctly numbered section 6 (37). The passage has two parts that mirror each other in an ebb and flow between uncertainty and confidence, what Tenney Nathanson identifies as the section's "oscillating rhythm" or "slipping back and forth." ${ }^{23}$ The child poses the question of the nature of grass and the poet, overcoming his initial hesitation and statement of ignorance ("I do not know what it is any more than he"), replies with five "guesses," each one penetrating ever deeper into the essence of the plant. ${ }^{24} \mathrm{~A}$ final answer culminates the poet's thinking and produces an assertion: "And now it seems to me the beautiful uncut hair of graves" (31). This line acts as the crucial hinge between the two parts of the section as the poet transitions from reflecting on the grass to reflecting on death. The final twenty-one lines are devoted to unspooling this new train of thought, considering death and its relationship to the natural environment, and are also characterized by an initial hesitation ("it may be") and a subsequent assertion of conviction, "there really is no death" (32). 
The dominant element of this passage is of course the figure of the grass, which Whitman uses throughout Leaves of Grass as a symbol of the physical nature of the book, the beauty of common objects, and even American democracy. However, in the line, "And now it seems to me the beautiful uncut hair of graves," Whitman moves from these poetic and political issues to the topic of death. In this moment, the grass ceases to be a wide-ranging symbol and becomes linked to a specific place: a cemetery. The "now" in this line signals an achieved understanding, a final perception of the meaning or use of the space. The grass grows over graves, a fact that requires the reader to go back and re-read the previous lines. This context suggests that the poet and child stand together before a grave and grants new poignancy to both the child's query and the poet's hesitation in responding; the question can now be seen to deal less with grass than with the grave it covers. The child is asking about the nature of life and death; that is, what allows grass to continue to grow while other living things die? The poet's initial statement of ignorance may also be seen as a delicate pause, contending with the loaded nature of the question and the innocence of the child: to define the grass is to offer an explanation of life and death to one as yet uninitiated to these realities. We may also interpret the poet's initial suppositions as an attempt to avoid the true nature of the question, instead directing the child's attention away from the grave and towards images of hope and life. Even the most explicitly political element of the passage, when Whitman writes that the grass means, "Sprouting alike in broad zones and narrow zones, / Growing among black folks as among white, / Kanuck, Tuckahoe, Congressman, Cuff, I give them the same, I receive them the same" (31), is rewritten within the context of a cemetery. These lines are conventionally interpreted as referring to how grass grows among a diverse group of people, symbolizing their essential equivalency. We must now consider that the "broad zones and narrow zones" refer to graves and that the four identified individuals are the deceased that inhabit a cemetery. Their equivalency is thus cemented not only by the grass that grows over them all but by death itself, the great equalizer.

If these lines refer to a rural cemetery, the grass that acts as the passage's central and unifying symbol is not a wild or native plant but one that has been deliberately cultivated. Although Whitman's grass symbology is typically read as a celebration of the untamed features of the natural world, the scene could reference instead the domesticated horticulture of a grassy cemetery lawn. If so, Whitman's reference to this landscape would have to be understood as an implicit deconstruction of the perfection of the rural cemetery. The passage opens with the child bringing the poet the grass, "fetching it to me with full hands" (31), an image of both abundance and destruction. Recall that one rural cemetery 
regulation was against picking flowers, so the child's act is a violation of the approved behavior within this controlled environment. Indeed, the fact that the grass is described as "uncut" implies that the setting may be a traditional or even an abandoned cemetery, in opposition to the tailored appearance of the rural cemetery. For Whitman, it is this imperfection that enables the poet's meditation; it is not accidental that the grass that the poet considers is uprooted and therefore dying. It is only through this physical disruption of the landscape, the killing of the plant that generates the poetic response, that the bittersweet parallels between life and death, destruction and creation may be perceived.

More significantly, viewing the passage within the context of the rural cemetery movement requires us to rethink the meaning of the four representative figures identified in the slangy phrase: "Kanuk, Tuckahoe, Congressman, Cuff." Whitman invokes these diverse types-a Canadian, an American Indian, a political leader, and an African-American man-in order to suggest that, despite the apparent differences of their nationality, race, and social status, they have a shared humanity. Whitman may have been citing real inhabitants of Green-wood Cemetery, which did include foreigners, American Indians, political leaders and African Americans. ${ }^{25}$ Whitman's list of these figures is intended to support, as it mirrors, the horizontal equivalence achieved in cemetery space: all are equal in death. The list even invokes an image of a line of headstones that identify the dead through a biographical shorthand in which national, social, familial and even racial characteristics are used to define their identities, narrowing the complexity of human experience to the few lines of an epitaph. However, if Whitman was inspired by the literal and literary landscape of the rural cemetery, he fails to account for the segregated or uneven structure of the space. In Green-wood Cemetery, a person's social status would have determined the manner in which they were commemorated, or even if they were welcomed within the cemetery. Likewise, the quality and significance of grave markers varied dramatically according to the wealth of the dead, ranging from individual burial plots with simple headstones to large family plots with ornate and towering monuments. In other words, Whitman may employ the literary tropes of the rural cemetery where they sync with his egalitarian message, but he selectively ignores the material reality of the space when it undercuts this optimistic rendition.

When Whitman turns directly to address the space of the cemetery with the transitionary line, "And now it seems to me the beautiful uncut hair of graves," his poetic gaze moves from the surface of the spacethat is, from the grass - to penetrate into the ground to reveal what lies beneath. In doing so, Whitman violates one of the unspoken rules of cemetery literature; he does not ignore the bodies. As we have seen, one 
consistent element in representations of rural cemeteries was to downplay the physical reality of the ground as a repository for corpses. This unpleasant feature was overwritten by the picturesque natural environment and the artificial decorations that keep the visitor's eye trained on the surface. Although the cemeteries promised to preserve the dead, they did so primarily through monuments, gravestones and statues. Whitman, however, rejects stone monuments by simply absenting them from the imaginary landscape of the passage and instead advocating the idea that the dead are preserved in or through nature. While, as I have suggested, Whitman employs the gravestone format of identifying the dead through a few, select features - as the passage progresses, increasingly through age and gender rather than nationality or race- these attributes are inscribed on the grass rather than on artificial monuments.

If the poet in Whitman's scenario had previously delayed in addressing death, here he turns towards it with a physical specificity that may have made nineteenth-century readers uncomfortable. The grass is granted bodily form; it is compared to hair, to the cradle of a lap, and to tongues speaking. This personification has the effect of unmasking the ground, peeling off the surface and revealing the bodies underneath. For Whitman, the practice of granting the natural environment a fleshy or bodily substance is not intended to highlight the grotesqueries of physical decay but rather to celebrate nature as a means of rebirth. Decay is not the pronounced theme that it will become in Whitman's later writing in poems like "This Compost," as here the physical structure of the bodies is preserved rather than eroded. The roofs of mouths, for example, remain intact even as they give rise to the "uttering tongues" of the grass. This is similar to what Killingsworth identifies as Whitman's "act[s] of incomplete identification," in which the parallels he establishes between humanity and nature allow the elements of nature to "maintain an integrity of their own." ${ }^{26}$ In this case, it is the natural features of the human body that are allowed to maintain integrity; Whitman resubstantiates the body as the primary feature of the dead rather than the disembodied characteristics inscribed on gravestones.

It is in the final stanzas of the section that Whitman's innovative use of the rural cemetery is made explicit. He takes the terms familiar to readers of cemetery literature - the beauty of death, the centrality of the cemetery in social relationships, the power of the cemetery to ward off sorrow-only to arrive at an understanding of death that implicitly rewrites the social function of the rural cemetery. The poet moves from an initial hesitancy in defining the relationship between the dead and nature-repeating the tentative phrase "it may be" — towards an radical assertion: "The smallest sprout shows there is really no death" (32). The concluding line succinctly summarizes the poet's new understanding: 
"And to die is different from what any one supposed, and luckier" (32). Analysis of the surprising conclusion of section 6 often centers on the contradictory structure of the passage, as it moves from a liberating indeterminacy of meaning to a fixed and declarative claim. ${ }^{27} \mathrm{My}$ analysis provides some context for understanding Whitman's poetic gesture, for the sentiment is a provocative engagement with the tropes of cemetery literature; visitors to Green-wood might have been tempted to look upon the picturesque setting as an implicit assertion that the best or only way to achieve a peaceful co-mingling with nature was through death. Considering the rural cemetery context also adds a note of irony to the affirmation since it draws attention to the fact that they were landscapes of privilege, that indeed the visitors and the interred were "lucky" to have access to the space. Moreover, Whitman's emphasis upon the dead challenges the conventional focus of the rural cemetery upon the living; most cemetery literature depicts the landscape as a stage from which the living gain new perspectives on and value of their own lives. Here, Whitman reverses this sense of perspective by suggesting that it is the dead that become comprehensible and achieve significance within their graves, regardless of the living.

While the poet is the one who accesses these insights - the repeated phrase "I perceive" reminds us of his importance to the process-the revelation is not for him or about him. Nor is it for the child interlocutor who has been replaced in the passage by a generic "you" and, in the final line, by an abstract "one." Nor, remarkably, does it appear to be for the reader; this is one instance when Whitman does not position the reader at his side, as may have been expected. ${ }^{28} \mathrm{By}$ the end of the section, Whitman has ceased in his attempts to make the cemetery meaningful or comprehensible to the living. The surface textures and forms, the "hints" that preoccupied the poet in the initial lines, have given way to a deeper, underground set of observations. It is the dead themselves that come into focus as meaningful - not for the meaning they grant to the living or grieving, but for their own "lives." In opposition to the ways that the rural cemeteries use the dead for entertainment, decoration, or inspiration, Whitman proposes that the ground is designed to serve the dead, as the humus for their organic rebirth and as the entrance to their spiritual afterlife.

My analysis has focused upon a thirty-two-line passage from the over thirteen-hundred-line "Song of Myself," upon one version of a poem of which there are seven published editions, and upon a single poem from Whitman's vast body of work. As such, my conclusions are necessarily limited in their scope and reflect only a moment in the poet's on-going engagement with the complex issue of death. Aspiz has suggested that Whitman's life-long attempts to explore the nature of existence and 
the possibilities of the afterlife from "every possible angle" means that "his pronouncements on death may even strike the reader as tentative, contradictory, or provocative" (3) ${ }^{29}$ Certainly, Whitman's writing about cemeteries continued to adapt to reflect changes in burial space, such as the Civil War practice of battlefield burial portrayed in the Drum-Taps poems. Yet, by situating Whitman's work within a specific cultural and literary context, we are better able to identify the points of influence and grasp the creative innovation of his evolving portrait of death. In this essay, I have suggested that the significance of the rural cemetery as both a material space and a literary image in the nineteenth century deserves reconsideration; Whitman's journalistic engagement with these memorial sites demonstrates what a powerful hold they had upon the popular imaginary, defining for many the very essence of the American cemetery. In his poetry, particularly in the "What is the Grass?" section of "Song of Myself," Whitman evokes the dominant forms of the rural cemetery only to reconceptualize the orientation of the space, inverting the landscape so that the dead are elevated to sight while the picturesque elements of the landscape, including the grass, are buried from view.

The University of Texas at Arlington

\section{NOTES}

1 The history and cultural significance of the rural cemetery movement in nineteenth-century America has been examined by Thomas Bender, "The 'Rural' Cemetery Movement: Urban Travail and the Appeal of Nature," Material Life in America, 1600-1860 (Boston: University Press of New England, 1988), 505-518; Gary Laderman, The Sacred Remains:American Attitudes towards Death, 1799-1883 (New Haven: Yale University Press, 1996); Blanche Linden-Ward, Silent City on a Hill: Landscapes of Memory and Boston's Mount Auburn (Columbus: Ohio State University Press, 1989); John F. Sears, Sacred Places: American Tourist Attractions in the Nineteenth Century (New York: Oxford University Press, 1989); and David Sloane, The Last Great Necessity: Cemeteries in American History (Baltimore: Johns Hopkins University Press, 1991).

2 Nehemiah Cleaveland, Green-wood Cemetery: A History of the Institution, from 1838 to 1864 (New York: Anderson \& Archer, 1866), 130-133.

3 Aspiz's sweeping and comprehensive analysis of death in Whitman's life and work constitutes the critical backdrop to the specific interests of this essay. See Harold Aspiz, So Long! Walt Whitman's Poetry of Death (Tuscaloosa: University of Alabama Press, 2004).

4 Edward Everett, "The Proposed Rural Cemetery," in Joseph Biglow, $A$ History of the Cemetery of Mount Auburn (Boston: J. Monroe and Co., 1860), 154-155. 
5 Michel Foucault identifies the rural cemetery movement as giving rise to a "heterotopia," as it creates two contrasting spaces of burial: the abandoned graveyard at the heart of the city and the new, idealized cemetery in the city's suburbs. Joseph Roach argues provocatively that, in light of the significant spatial gap between the living and the dead created by the rural cemetery movement, "modernity itself might be understood as a new way of handling (and thinking about) the dead." See Foucault, "Of Other Spaces," trans. Jay Miskowiec, Diacritics 16 (Spring 1986), 25; and Roach, Cities of the Dead: Circum-Atlantic Performance (New York: Columbia University Press, 1996), 48.

6 D. B. Douglass, Exposition of the Plan and Objects of the Green-wood Cemetery, An Incorporated Trust (New York: Narine \& Co., 1839), 12.

7 G.T.C., "Mount Auburn," New-England Magazine (October 1834), 316-317. Hereafter G.T.C.

8 "Mount Auburn Cemetery," The North American Review 33 (October 1831), 406.

9 Cornelia W. Walter, Mount Auburn Illustrated, illustrations by James Smillie (New York: R. Martin, 1847), 14.

10 Nehemiah Cleaveland, Green-wood Illustrated, illustrations by James Smillie (New York: R. Martin, 1847), vii.

11 Nathaniel Dearborn, Dearborn's Guide Through Mount Auburn, with sixty-four engravings of the monuments for the Benefit of Strangers . . , $5^{\text {th }}$ edition (Boston, 1851), 5 .

12 A.D.G., "Rural Cemeteries," Horticulturalist and fournal of Rural Art and Rural Taste 6 (June 1, 1855), 279.

13 Anna, "Lingerings with Nature: No. 3: Greenwood Cemetery." National Era 11 (November 26, 1857), 189.

14 Jill Wacker has examined the panoramic view in the depiction of public space as a defining metaphor in Whitman's early journalism and poetry, including in his writing about rural cemeteries, in "Sacred Panoramas: Walt Whitman and New York City Parks," Walt Whitman Quarterly Review 12 (Fall 1994), 86-103.

15 Knickerbocker, "Fugitive Sketches," The Pearl and Literary Gazette 3 (October 26, 1833), 50.

16 Lydia Sigourney, "Visit to Greenwood Cemetery," Graham's American Monthly Magazine of Literature, Art, and Fashion 33 (July 1848), 53. 
17 For specific discussions of the restrictions on access to the rural cemeteries based on race, class, and religion, see Linden-Ward, Silent City, 184-187 and 312, and Sloane, Last Great Necessity, 53-69 and 83. For a broader history of race in American cemeteries, see Angelika Kruger-Kahloula, "On the Wrong Side of the Fence: Racial Segregation in American Cemeteries," History and Memory in African American Culture, ed. Geneviève Fabre and Robert O'Mealy (Oxford: Oxford University Press, 1994), 130-149.

18 Jacob Bigelow, A History of the Cemetery of Mount Auburn (Boston: J. Monroe and Co., 1860), 29-30, 252-253.

19 For more on the literary presence of these rural cemeteries, see Blanche Linden-Ward, "Strange but Genteel Pleasure Grounds: Tourist and Leisure Uses of Nineteenth-Century Rural Cemeteries," in Cemeteries and Gravemarkers: Voices of American Culture, ed. Richard Meyer (Ann Arbor: UMI Research Press, 1989), 294-328.

20 Whitman's articles on Green-wood are: "Greenwood Cemetery" (November 16, 1839); "A Visit to Greenwood Cemetery" (May 5, 1844); "City Intelligence: An Afternoon at Greenwood" (June 13, 1846); "Literary Notices: Greenwood Illustrated" (August 15, 1846); "The Literary World: Greenwood Illustrated" (October 13, 1846); "An Afternoon with the Orphans-Ride to Greenwood ..." (June 14, 1847); and "Philosophy of Ferries" (August 13, 1847). All are reprinted in Whitman, The fournalism, ed. Herbert Bergman et. al., 2 vols. (New York: Peter Lang, 1998, 2003); citations to specific articles are included in the text. Hereafter fournalism.

21 M. Wynn Thomas, "Whitman's Tale of Two Cities," American Literary History 6 (1994), 634.

22 Quoted in fournalism, $1: x x v$.

23 Tenney Nathanson, Whitman's Presence: Body, Voice, and Writing in Leaves of Grass (New York: New York University Press, 1992), 400-401.

24 All quotations of Whitman's poetry are from the 1855 edition of "Song of Myself" in Complete Poetry and Collected Prose (New York: Library of America, 1982) and are cited by page number in the text.

25 I have been unable to identify specific individuals interred in Green-wood Cemetery to correspond with Whitman's four representative figures, the "Kanuk, Tuckahoe, Congressman, Cuff." However, there is ample evidence that a diversity of individuals were interred in the cemetery, including foreigners, American Indians, political leaders and African Americans, which correspond with the general characteristics of Whitman's types. 
26 M. Jimmie Killingsworth, Walt Whitman and the Earth: A Study in Ecopoetics (Iowa City: University of Iowa Press, 2004), 33, 34.

27 For example, Kerry C. Larson describes this as "a sudden rift between a poetry of diffusion whose signifier (the grass) ranges effortlessly through a field of significances and a poetry of reduction which seeks relief from such indeterminacy," and critiques "the way it protests against reductiveness in a manifestly reductive fashion." See Larson, Whitman's Drama of Consensus (Chicago: University of Chicago Press, 1988), 119-120.

28 The poetic "I" and the implied reader are resurrected in the subsequent couplet: "Has any one supposed it lucky to be born? / I hasten to inform him or her it is just as lucky to die, and I know it" (32). However, these lines are shifted into section 7 of "Song of Myself" after the first edition, suggesting a formal division even though the subject matter is consistent.

29 Aspiz affirms that, despite the variety of positions explored in Whitman's writing about death, a single concept, which he describes as "resound[ing] like an iron chord in Leaves of Grass," is persistent throughout: the poet's conviction of the existence of an afterlife. See, for example, Aspiz, 1-2. 